\title{
Zum Texte des Tritojesajas.
}

Von Prof. Dr. F. Praetorius in Breslau.

Jes $569-12$ heben sich nach Form und Inhalt vom Vorhergehenden und Folgenden ab. In v. 1o deutet schon der große Anfangsbuchstabe mit Wahrscheinlichkeit darauf hin, daß hier ein neues Stück beginnt. Außerdem aber werden v. to und II durch das gemeinsame fünffußige Versmaß zusammengehalten.:

Wenn mit צ' also wahrscheinlich ein neues Stück begonnen hat, so ist es weiter wahrscheinlich, daß das Qerē rọ nicht richtig ist. Denn es wäre immerhin auffallend, wenn ein Stück mit einem Possessivpronomen der 3. Person begänne. Das Qerē ist wohl erst ersonnen worden, nachdem das Stuick in den jetzigen Zusammenhang eingefugt worden war.

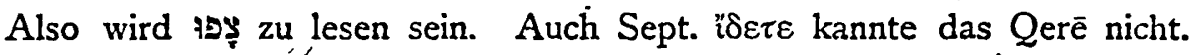

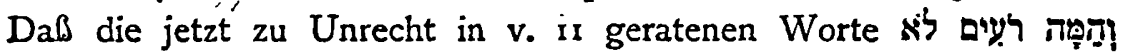

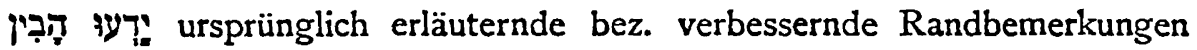
waren, ist längst erkannt worden. Ob לו̣ oder in v. ro ebenso zu beurteilen ist, oder ob in ihm ein Rest des zu Anfang verstümmelten dritten Fünfers vorliegt!, wird mit Sicherheit kaum auszumachen sein. Ich nehme vermutungsweise das letztere an. $\mathrm{DaD}$ das auch in Sept.

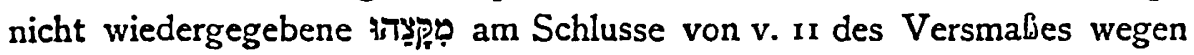
zu streichen ist, kann nicht zweifelhaft sein. Demnach dürften sich v. to und II des MT so darstellen:

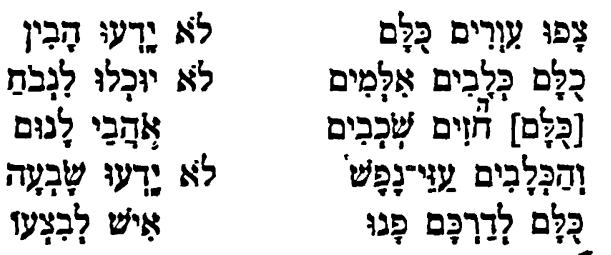

Auffallend ist, daß nicht nur מִּקָ in Sept. fehlt, sondern auch der

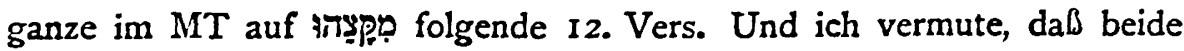
Erscheinungen in engem Zusammenhange mit einander stehen, d. h. daß Qִק ursprünglich auch zu v. 12 gehört. Und zwar in folgender Weise: Ebenso wie in Erinnerung an Jer I 2 10, Hes 342 und ähnliche Stellen Zeitschr. f. d. aittest. Wiss. Jahrg. 33. $19 \times 3$. 
die Erläuterung והטה רעים an den Rand geschrieben worden ist, so

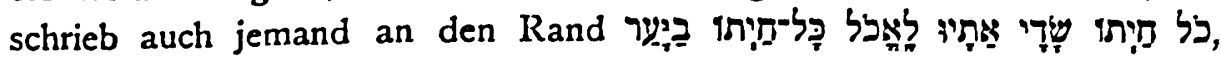
wahrscheinlich aus einem uns verlorenen Gedichte genommen. Und

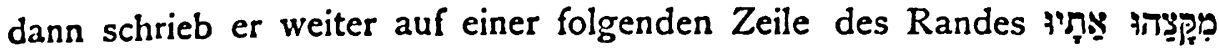

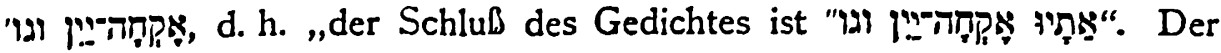
Gedanke, dab da wo es Schlachtopfer gibt, die.Tiere ihre Speise finden, findet sich mehrfach in ähnlicher Gestalt im AT ausgesprochen; und auch der Schreiber dieser Randbemerkung wollte aus Veranlassung des Textinhaltes durch seine Randbemerkung diesem Gedanken Ausdruck geben. Später wurde dann der erstere Vers am Schlusse des vorhergehenden Stijckes (als v. 9 des MT) eingeschoben, und noch später

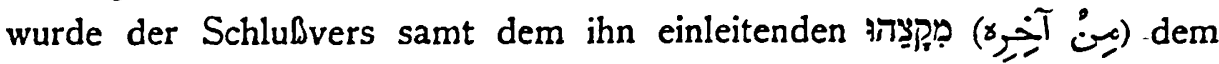
zugehörigen Textstücke selbst angehängt (als v. 12 des MT). An den Enden von selbständigen Textstücken war viel freier Platz, „der sozusagen zum Anschieben einlud" (SIEvers, Metrische Studien I, S. 369).

$\mathrm{Da} ß$ die Verse 9 und 12 inhaltlich vortrefflich zu einander stimmen, wîrd nicht zu leugnen sein. Aber auch metrisch stimmen sie überein. Es sind beides Sechser. In v. 12 reicht der Sechser bis

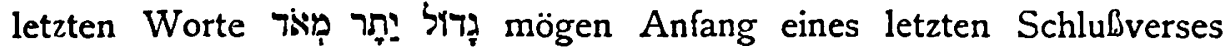
sein, oder ein abschließender Kurzvers. -

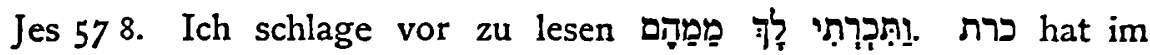
AT öfters $\underline{\underline{n}}$ als Objekt. Über den obscönen Sinn an dieser Stelle wird wohl im vorliegenden Zusammenhange kein $Z$ weifel aufkommen können. -

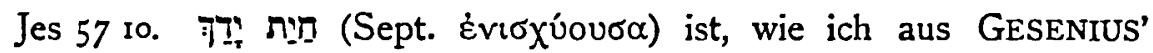
Handwörterbuch ${ }^{25}$ S. 224 ersehe, von OORT in " "חָ verändert worden. Ich glaube, daß diese, übrigens recht nahe liegende Verbesserung schon von einem alten jüdischen Schreiber an den Rand geschrieben worden ist. Am Schlusse von v. 8 lesen wir nämlich das rätselhafte, in Sept.

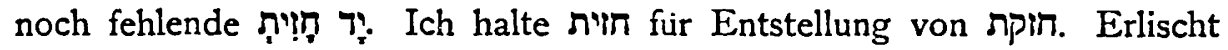
der oft sehr feine Grundstrich des $\beta$, so bleibt ein etwas großes 'übrig. Ich vermute also, daß ein Schreiber das fehlerhafte יָּ חיר

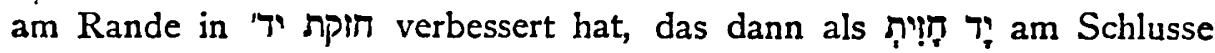
des 8. Verses in den Text eingedrungen ist und die Erklärer gepeinigt

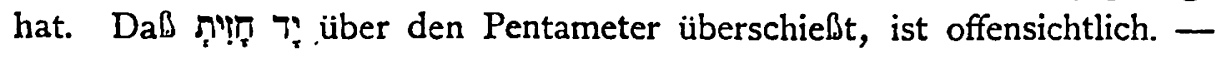
Jes 57 19. Die ersten drei Worte fehlen in Sept. Ich vermute sị

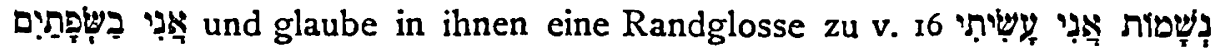
zu erkennen. Ein Leser dachte bei dieser Stelle wohl an Gen 27 und schrieb eine den Sinn der Stelle aus Gen 27 erläuternde Bemerkung 
an den Rand. Diese ist verstümmelt und an unrechter Stelle in den Text gedrungen. -

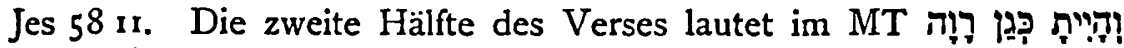

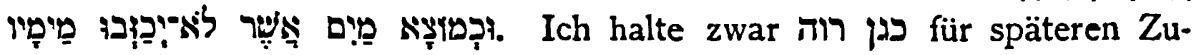
satz; aber Sept. hatte ihn bereits. Und auf Grund des vorliegenden Textes nahm ein Leser Anstoß an מיטיו Er und erwartete dafür מין Er wollte den Text so verstehen: „Und du wirst sein wie ein bewässerter Garten; und wie eine Quelle nicht versiegenden Wassers (wird sein) dein

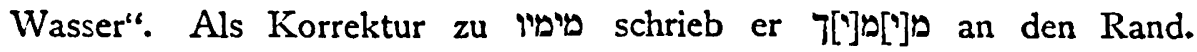
Diese Randbemerkung ist dann als zweites Wort in den folgenden Vers geraten und hat Veranlassung gegeben zu den vielgequalten Worten

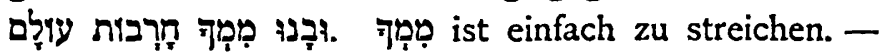

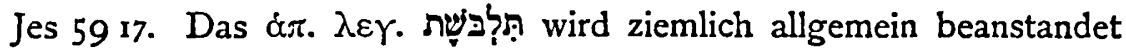
und gestrichen. Es verstöbt in der Tat auch gegen das Metrum. Ich glaube, es läbt sich auch noch wahrscheinlich machen, woher dieses

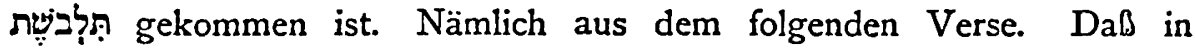

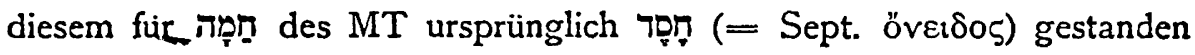
hat, ist - wie ich aus DUHM zur Stelle entnehme - bereits von anderen angenommen worden. Aber חֶָָ ist zweideutig. Deshalb veränderte es ein Schreiber in הָָָn, sich möglichst eng an die Form der Buchstaben von חסר anschließend. Ein anderer aber ließ das zweideutige חס im Texte zwar stehen, erklärte es aber am Rande durch בשֶָת. Diese erklärende Randglosse wurde später irrtumlich in den 17 . Vers einbezogen, in dem von Kleidungsstuicken und Bekleiden die Rede ist. Daher dann die Ergänzung zu תשב[ל]]. -

Jes 64 I. An Stelle des unverständlichen MT zu Beginn des Verses

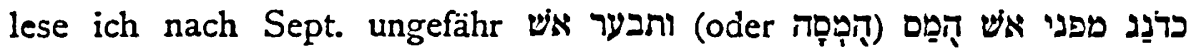

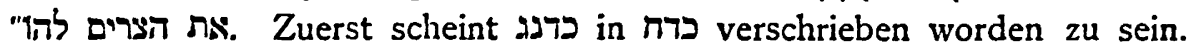
Dies wurde, weil sinnlos, in כקדת verändert; und der Bedeutung dieses Wortes zu liebe wurde nun das nächstfolgende zerstört, d. h. מפע wurde

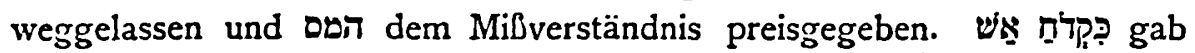

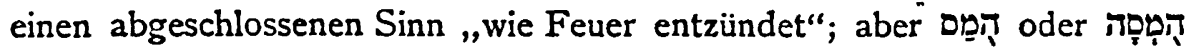
war ohne jede Beziehung. Um die nötige Beziehung zu geben, wurde המסה המס zugefügt: Sym. Ė als eine, vielleicht mit dem Artikel versehene Nominalform angesehen und in Kongruenz zu a gebracht, - Nachträglich sah ich, dab ZILLESSEN in ZAW Bd. 26, 272f. die Stelle im wesentlichen bereits ebenso beurteilt hat. 